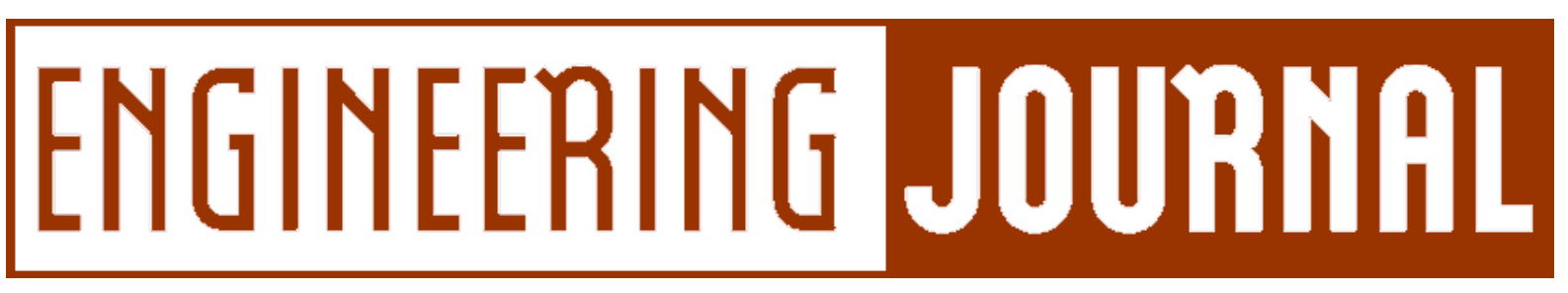

Article

\title{
Evaluating Damaged Concrete Depth in Reinforced Concrete Structures under Different Fire Exposure Times by Means of NDT and DT Techniques
}

\author{
Totsawat Daungwilailuk ${ }^{1, a}$, Thi Nguyen Cao ${ }^{2, b,}$, Withit Pansuk ${ }^{2, c}$, \\ and Phoonsak Pheinsusom ${ }^{2, \mathrm{~d}}$ \\ 1 Department of Civil and Environmental Engineering, Hiroshima University, Hiroshima, Japan \\ 2 Innovative Construction Materials Research Unit, Department of Civil Engineering, Faculty of \\ Engineering, Chulalongkorn University, Bangkok, Thailand \\ E-mail: ad156057@hiroshima-u.ac.jp, bcaonguyenthi@tgu.edu.vn (Corresponding author), \\ cWithit.P@chula.ac.th, dPhoonsak.P@chula.ac.th
}

\begin{abstract}
After a severe fire, concrete structures are generally capable of being repaired rather than demolished. To determine whether the fire-damaged structure can be repaired, an assessment of structural integrity must be conducted. In this research, a laboratory assessment of fire-damaged reinforced concrete (RC) slabs was carried out by using Destructive Testing (DT) and Non-Destructive Testing (NDT) techniques. The study aimed to evaluate the depth of damaged concrete in RC slabs exposed to fire for different periods of time (30, 60, 90 and 120 minutes) based on the correlation between the experimental results of DT and NDT methods. The experiment was conducted with two concrete grades of 24 and $35 \mathrm{MPa}$. Limestone aggregates were used in this study. The experimental results indicated that 30 minutes of heating time did not show severe effects on reinforced concrete slabs in comparison with the other cases. A damaged concrete layer of $30-45 \mathrm{~mm}$ was observed for slabs exposed to fire in 60 and 90 minutes. Besides, 24 MPa slabs also showed a lower damage level compared with $35 \mathrm{MPa}$ slabs.
\end{abstract}

Keywords: Fire-damaged concrete, destructive test, non-destructive test, Schmidt rebound hammer, ultrasonic pulse velocity, pull-off test. 


\section{Introduction}

\subsection{Background}

A deterioration in the properties of reinforced concrete (RC) structures occur when it subjected to fire. Of particular importance are loss in compressive strength; loss of elastic modulus; cracking and spalling of the concrete; reduction of yield strength, ductility and tensile strength of the steel; and loss of the bond between the concrete and steel [1]. Although the concrete structure may be damaged during a fire, it can retain a certain amount of residual load bearing capacity [2]. Therefore, repairing and strengthening the fire-damaged structures can be an option as opposed to the costlier alternative of rebuilding the structure. To determine whether a fire-damaged structure can be repaired or to evaluate the state of a member after exposure to fire would require an investigation of its structural integrity.

Over the past few decades, a number of assessment techniques have been used to determine the condition of concrete and the internal changes to the physical properties of the material after exposure to high temperatures. The techniques include various methods such as a Schmidt Rebound Hammer, Ultrasonic Pulse Velocity (UPV), Differential Thermal Analysis (DTA), Thermal Gravimetric Analysis (TGA), calorimetry, micro-crack density analysis, petrographic analysis, image analysis, and others [2]. These tests employed in the assessment of fire-damaged structures can be divided into two types: in situ techniques and laboratory tests. The situ techniques can be applied on the concrete surface by using Non-Destructive Testing (NDT) methods such as UPV or a Schmidt Rebound Hammer. The advantages of in situ techniques are the possibility to estimate a large area of a damaged building and the short time required to perform the tests. Although they are convenient and practical, the information from NDT is limited in the depth of firedamaged layers inside the concrete. To successfully observe the damage depth, a laboratory test such as a core drilled out of the concrete member is preferable. Valuable information can be determined on a core such as the depth of the fire damage using petrographic analysis [3], color change analysis or determination of the remaining loading capacity by compression testing.

\subsection{The Response of Concrete to Fire}

During a fire, the temperature in the concrete mass will rise, causing thermal expansion of the constituents, evaporation of moisture, and buildup of pore pressure [4]. Two principal effects of fire on structural concrete can be observed: (1) loss in strength of the matrix by degradation of the hydrate structure and (2) spalling and "shelling" of the outermost concrete [5].

The physical effects and color change in concrete depend on the change in temperature. During heating above $300^{\circ} \mathrm{C}$, the color of concrete can change to pink $\left(300-600^{\circ} \mathrm{C}\right)$ then to white/gray $\left(600-900^{\circ} \mathrm{C}\right)$ and to buff $\left(900-1000^{\circ} \mathrm{C}\right)[6,7]$. When the temperature is between $100^{\circ} \mathrm{C}$ and $200^{\circ} \mathrm{C}$, evaporation of free moisture in concrete occurs, which can result in spalling due to high internal steam pressures. As the temperature reaches $250^{\circ} \mathrm{C}$, dehydration occurs. At $300^{\circ} \mathrm{C}$, strength reduction occurs in the range of $15-40 \%$ and $55-70 \%$ at $550^{\circ} \mathrm{C}$ because of calcium hydroxide dehydration $[6,8]$. At temperatures of $550^{\circ} \mathrm{C}$, aggregates begin to deteriorate. Quartz in siliceous aggregates polymorphically changes with a volumetric expansion and consequent damage. In limestone aggregate concrete, $\mathrm{CaCO}_{3}$ turns into $\mathrm{CaO}$ at $800-900^{\circ} \mathrm{C}$, and further expands with temperature [9].

Spalling is often mentioned as an important consequence in post fire evaluation of structural concrete exposed to fire. Spalling is the breaking-off of layers of the concrete surface in response to applied heat [5]. It may cause the loss of sections of concrete elements or create fire damage depth on exposed surfaces while reducing the protective ability of the reinforcement. Concrete spalling is attributed to the loss in tensile strength of concrete at high temperatures [10] and could be grouped into the following categories: aggregate spalling, corner spalling, surface spalling and explosive spalling [11]. All forms of concrete spalling may cause fire resistance failure through loss of load-bearing capacity or loss of integrity [12].

\subsection{The Response of Concrete to Fire}

Assessment of concrete usually starts with visual observation of color change, crazing, cracking and spalling [13]. In this study, visual observation in an assessment of fire-damaged slabs includes the investigation of concrete spalling areas as well as the change of color on the surface. The assessment with NDT techniques 
are carried out using Ultrasonic Pulse Velocity and the Schmidt Rebound Hammer method to quickly estimate the state of fire damage to the structure and the degradation depth of the concrete. Moreover, the evaluation from pull-off testing and cores samples from the fire-damaged members supply data to verify the results of the NDT techniques.

\subsection{The Objectives}

This research aims to evaluate the depth of damaged concrete layers under different burning time by means of NDT and DT applied to RC slabs. These experimental results can be useful in supplying data for other studies that aim to repair and strengthen fire-damaged reinforced concrete slabs.

\section{Experimental Program}

The tests were conducted in the Fire Safety Research Center and the Concrete Laboratory at Chulalongkorn University, Bangkok, Thailand. The experimental program consisted of two parts: fire tests on RC slabs and the assessment of specimens after fire.

\subsection{Material Properties and Specimen Configuration}

Reinforced concrete slabs were designed under standard ACI 318-08 [14] and cast in the Concrete Laboratory for a total number of 10 specimens. The design of the slabs is shown in Fig. 1. Ready mixed concrete was used with two concrete grades of 24 and $35 \mathrm{MPa}$. The concrete was made with limestone aggregate as this is the usual aggregate used in Thailand. The slabs had dimensions of 1,000x900x150 mm and were reinforced longitudinally with $10 \mathrm{~mm}$ diameter steel bars. Only one side in each slab was exposed to fire. Among the specimens, two were used as control specimens while the others were subjected to fire. The details of all specimens are shown in Table 1.

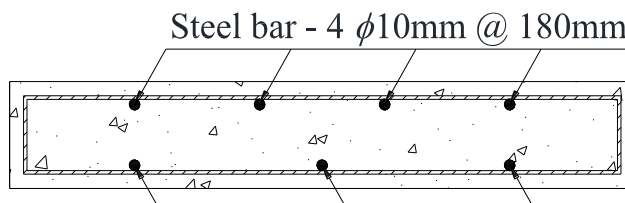

Steel bar - $3 \phi 10 \mathrm{~mm} @$ 270mm A-A
1000

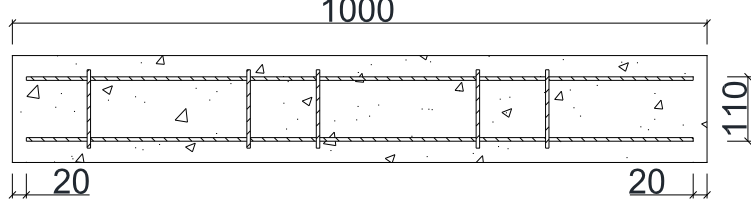

B-B

$œ$

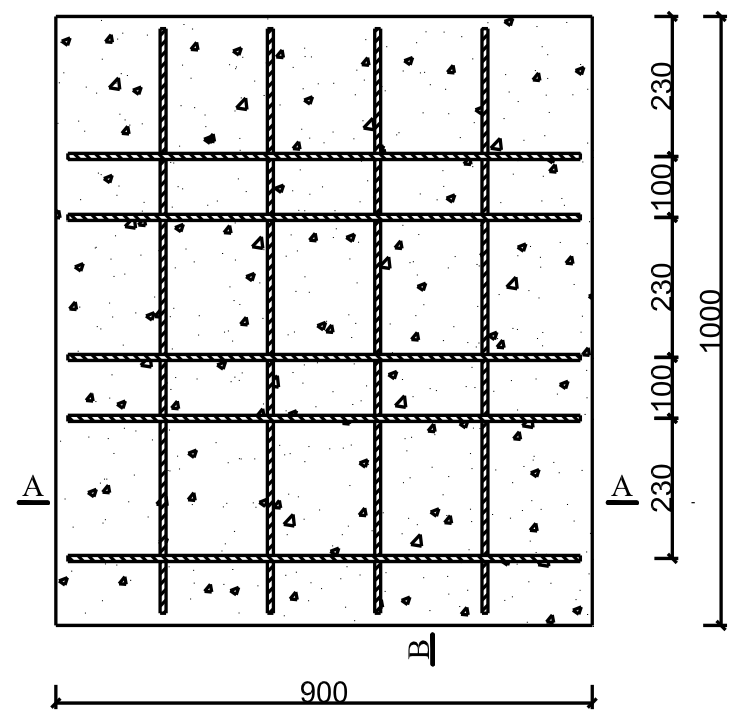

Fig. 1. The design of the RC slabs. 
Table 1. Details of specimens.

\begin{tabular}{llll}
\hline Specimen No. & Concrete grade (MPa) & Fire time (minutes) & Concrete cover $(\mathbf{m m})$ \\
\hline S240002 & 24 & 0 & 20 \\
S240302 & 24 & 30 & 20 \\
S240602 & 24 & 60 & 20 \\
S240902 & 24 & 90 & 20 \\
S241202 & 24 & 120 & 20 \\
S350002 & 35 & 0 & 20 \\
S350302 & 35 & 30 & 20 \\
S350602 & 35 & 60 & 20 \\
S350902 & 35 & 90 & 20 \\
S351202 & 35 & 120 & 20 \\
\hline
\end{tabular}

\subsection{Fire Test}

The conditions of the fire test were operated under ASTM E119 standard [15]. The specimens were cured for 1 month before testing in a furnace. To evaluate the effect of heating time, the slabs were divided into four groups corresponding to fire exposure times of 30, 60, 90 and 120 minutes. In every specimen, five sides were covered by high temperature insulation consisting of ceramic fiber wool to ensure that only one surface would be exposed to the fire (Fig. 2). Moreover, the thermocouples were also installed at four different depths $(0,25,75$ and $125 \mathrm{~mm})$ from the exposure surface to record the temperature during the test.
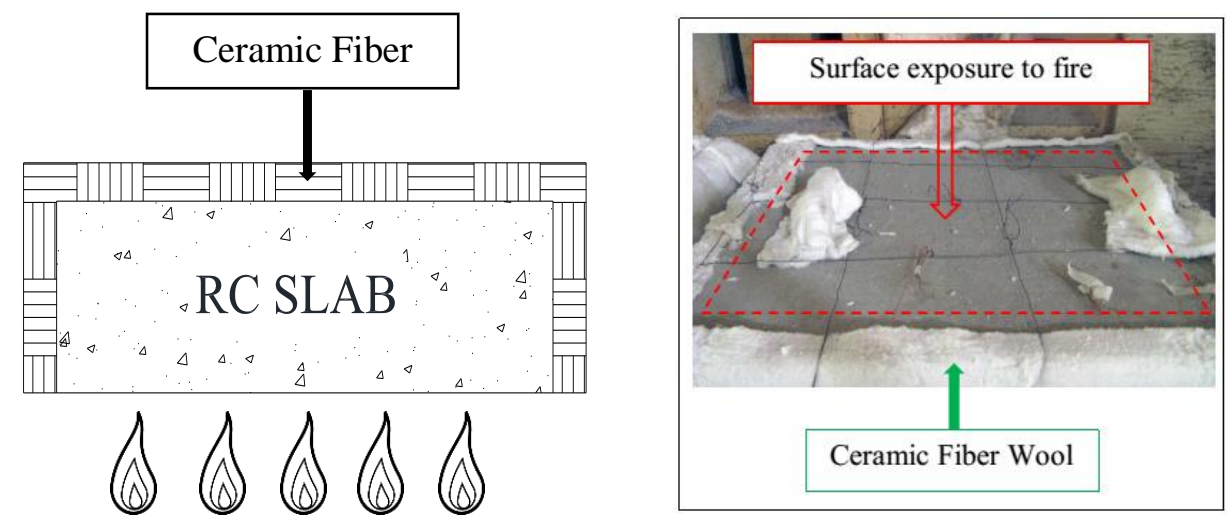

Fig. 2. Slabs were covered in ceramic fiber wool on 5 sides before the test.

\subsection{Assessment of Fire Damage with Non-Destructive Testing}

\subsubsection{Visual inspection}

After the fire test, all of the specimens were moved from the furnace and stored at room temperature for three days. The first assessment consisted of a visual observation for every slab to determine the degree of damage to the exposure surfaces. This evaluation was performed by using a transparent plastic plate as shown in Fig. 3. The plastic plate had dimensions of $60 \times 60 \mathrm{~cm}$ and was divided into 144 small rectangles with dimensions of $5 \times 5 \mathrm{~cm}$. Using this method, the area of concrete spalling could be drawn on the plastic plate before being calculated. In this research, the degree of damage on exposure surface was quantified based on the criterion:

$$
\text { Damage degree }=A_{s} / A_{c}
$$

where $A_{s}$ is the area of concrete spalling on the exposure surface and $A_{c}$ is the total area of the concrete surface before testing. 


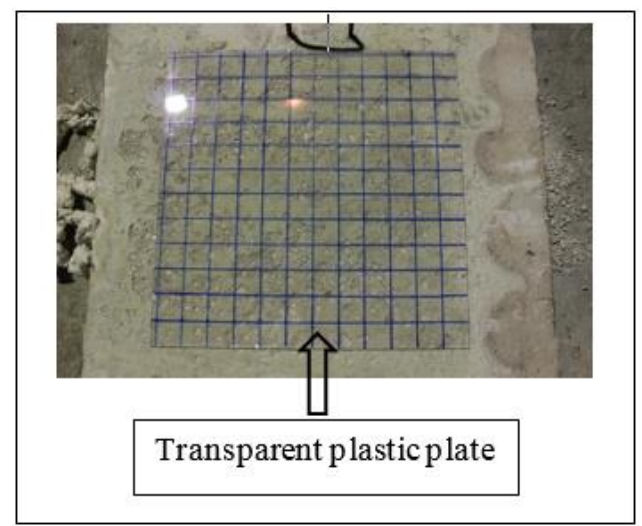

Fig. 3. Transparent plastic plate on exposure surface.

\subsubsection{Ultrasonic pulse velocity (UPV)}

Following the visual inspection, UPV testing was performed to measure the depth of the fire-damaged concrete layer. This test was conducted under standard ACI 228.2R-98 [16] based on the following principle: the speed of propagation of stress waves depends on the density and the elastic constants of the solid. The fire-damaged layer has a lower wave speed than the underlying non-damaged concrete. This test can be depicted as shown in Fig. 4. The method assumes that the stress waves' arrival at the receiver occurs along two paths: Path 1, which is directly through the damaged concrete, and Path 2, which is through the damaged and the non-damaged concrete. For small separations, the travel time is shorter for Path 1, while for large separations, the travel time is shorter for Path 2. By plotting the travel time as a function of the distance $X$, the presence of the damaged surface layer is indicated by a change in the slope of the data. The depth of the damaged layer is found from the following:

$$
d=\frac{x_{0}}{2} \sqrt{\frac{V_{s}-V_{D}}{V_{S}+V_{D}}}
$$

where $\mathrm{X}_{0}$ is the distance in which the travel times for the two paths are equal and is found from the intersection of the straight lines in Fig. 4 (b). $V_{S}$ and $V_{D}$ are the wave speeds in the damaged and the nondamaged concrete.

In this experiment, the UPV test was performed with a frequency of $54 \mathrm{kHz}$ and the measured positions were marked by lines with intervals of $100 \mathrm{~mm}$. Data were collected both forwards and backwards in each line (Fig. 5).
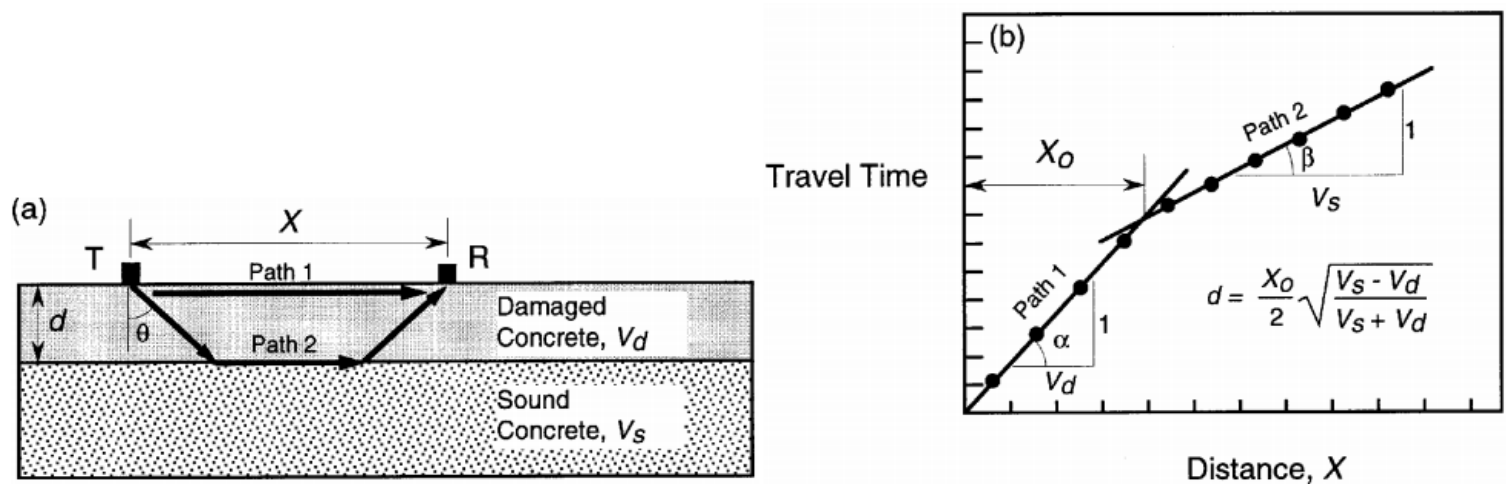

Fig. 4. (a) Wave paths for ultrasonic testing on surface of concrete with a damaged surface layer; and (b) Travel time as a function of distance between transmitter and receiver [16]. 


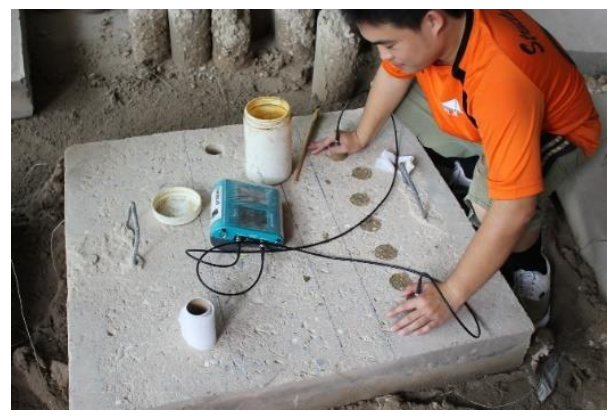

Fig. 5. UPV test on fire-damaged slabs.

\subsubsection{Schmidt rebound hammer}

Another NDT method, the Schmidt Rebound Hammer, was performed on the fire-damaged surface to determine the surface hardness of the concrete in each slab. The test was carried out on six locations of each slab and 16 testing points were recorded on each location (Fig. 6). This test was conducted based on standard ASTM C805 / C805M-13a [15].

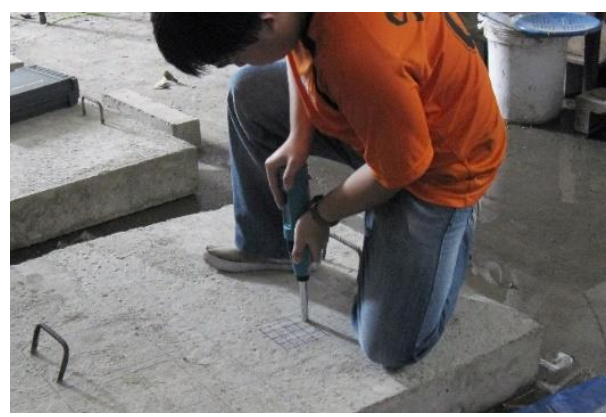

Fig. 6. Schmidt rebound hammer test.

\subsection{Assessment of Fire Damage with Destructive Testing}

Two other destructive tests, coring tests and pull-off tests, were conducted to give supplementary data that could be useful for providing more information about the state of the concrete in the fire-damaged specimens.

\subsubsection{Coring test}

To determine the depth of color change due to fire exposure, a coring test was conducted. Although the method consists of expensive and time consuming operations, cores give reliable and useful results because they are mechanically tested to destruction [17]. The test was performed under standard ASTM C 42/C 42M03 [18] and four concrete cores with a diameter of $50 \mathrm{~mm}$ were drilled in each slab.

\subsubsection{Pull-off test}

This test was performed based on standard ASTM C1583-04 [19] to evaluate the tensile strength at three depth levels of 10, 20 and $30 \mathrm{~mm}$ on the exposure side. In each slab, nine positions were located and divided into three groups that corresponded with three depth levels (Fig. 7). Then, the concrete in each group was carefully removed using a drilling machine operated until the maximum level of its cutting depth, as shown in Fig. 8. All of the new surfaces after cutting were grinded to prepare for the pull-off test (Fig. 9). A $50 \mathrm{~mm}$ diameter circular steel disk was attached to the new surface by epoxy adhesive (Fig. 10). The force required to pull the disc from the concrete surface by hand-operated loading equipment was measured and calculated to obtain the tensile strength. 


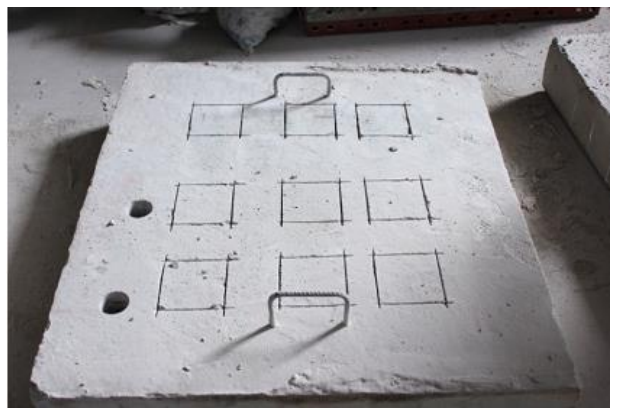

Fig. 7. The positions were located for the pull-off test.

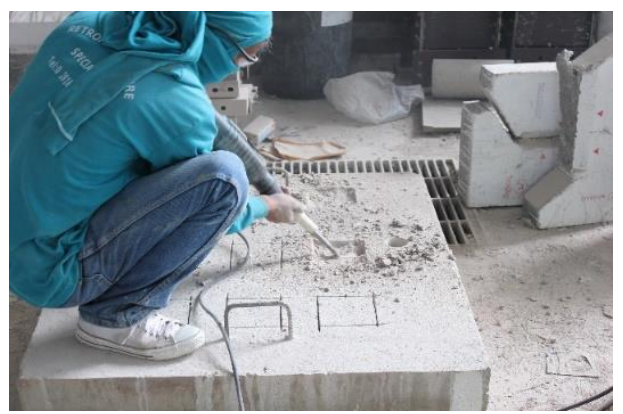

Fig. 8. Removing concrete via drilling machine.

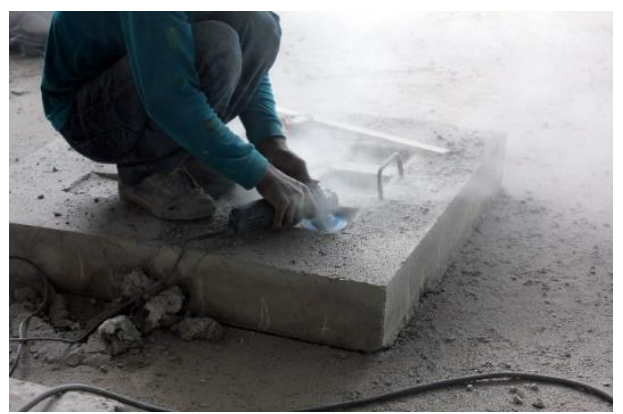

Fig. 9. Smoothing the surface of concrete.

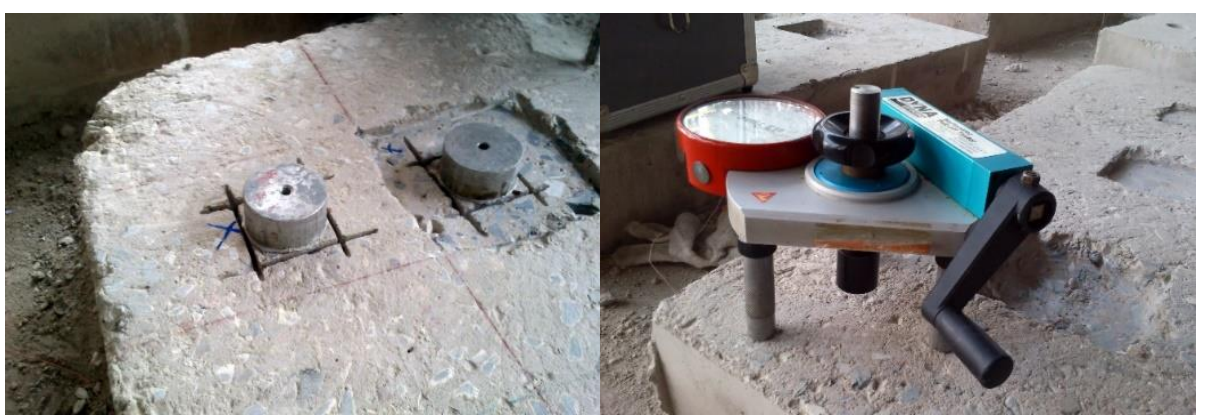

(a)

(b)

Fig. 10. Installing pull-off test: (a) the steel disk; (b) the tensile loading device. 


\section{Test Results and Discussions}

\subsection{The Distribution of Highest Temperature}

The maximum temperature at the exposure surface and three other depth levels $(25,75,125 \mathrm{~mm})$ in each specimen are reported in Table 2. Moreover, the change of the highest temperature on the depth of concrete is represented in Fig. 11 and Fig. 12. Due to the breaking of thermocouples in the depths of 75 and $125 \mathrm{~mm}$, the values of maximum temperature at these positions were not recorded in the case of slab S351202. However, it could be observed in all specimens that temperature generally reduced corresponding to increased depth from the exposure surface as concrete is a poor conductor of heat [5], due to its incombustible nature and its low thermal diffusivity, which guarantee a slow propagation of thermal transients within the structural members [20].

In all cases, the increase of fire exposure time led to the increase of temperature at every evaluating location. However, the increase became significant as the time surpassed 60 minutes. At the depth of $25 \mathrm{~mm}$, the temperature increased $30^{\circ} \mathrm{C}$ as the fire exposure time reached 60 minutes compared with the heat increase at 30 minutes. Meanwhile, the heat increased more than $250^{\circ} \mathrm{C}$ as the time rose over 90 minutes in comparison with the heating time of 30 minutes. This change was observed in both series of 24 and $35 \mathrm{MPa}$ concrete.

Regarding to the alteration of temperature on further depth, the heat dropped through concrete over 25 $\mathrm{mm}$ with a reduction of approximately $600^{\circ} \mathrm{C}$. Nevertheless, the decrease became smaller at deeper levels.

Table 2. The maximum temperature recorded at the fire exposure surface.

\begin{tabular}{lllll}
\hline $\begin{array}{l}\text { The } \\
(\mathbf{m m})\end{array}$ & $\begin{array}{l}\text { depth } \\
\text { No. }\end{array}$ & $\begin{array}{l}\text { Specimen } \\
\text { Noximum temperature } \\
\left({ }^{\circ} \mathbf{C}\right)\end{array}$ & $\begin{array}{l}\text { Specimen } \\
\text { No. }\end{array}$ & $\begin{array}{l}\text { Maximum temperature } \\
\left({ }^{\circ} \mathbf{C}\right)\end{array}$ \\
\hline 0 & & 803 & & 881 \\
25 & S240302 & 108.6 & S350302 & 125.7 \\
75 & & 46.3 & & 49.7 \\
125 & & 45.2 & & 48.7 \\
0 & & 799 & & 868 \\
25 & & 129.1 & S350602 & 175.5 \\
75 & S240602 & 127.5 & & 123.7 \\
125 & & 84.1 & & 117.5 \\
0 & & 949 & $\mathrm{~S} 350902$ & 353 \\
25 & & 358.4 & & 314.2 \\
75 & $\mathrm{~S} 240902$ & 131 & & 196.8 \\
125 & & 130.7 & & 134.7 \\
0 & & 1015 & $\mathrm{~S} 351202$ & 437.9 \\
25 & & 446.8 & & - \\
75 & $\mathrm{~S} 241202$ & 188.8 & & - \\
\hline
\end{tabular}




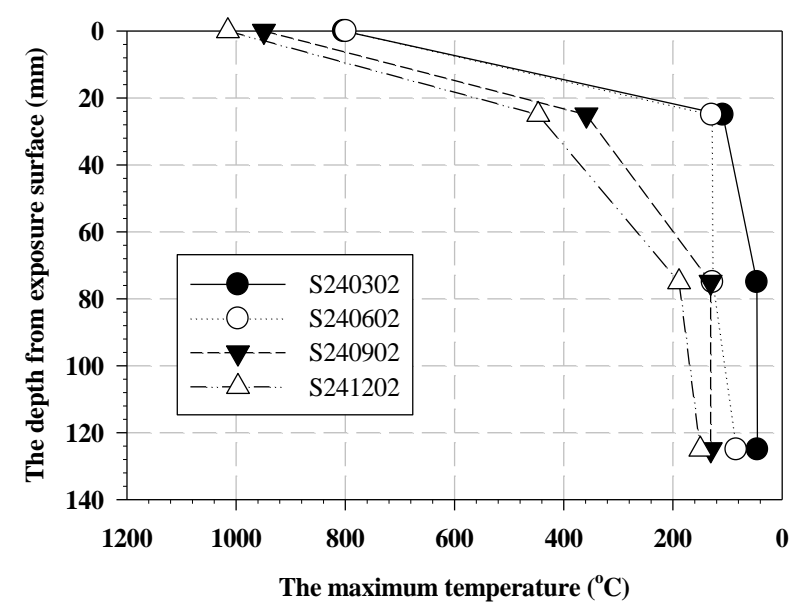

Fig. 11. The maximum temperature recorded at different depth levels for the $24 \mathrm{MPa}$ slab.

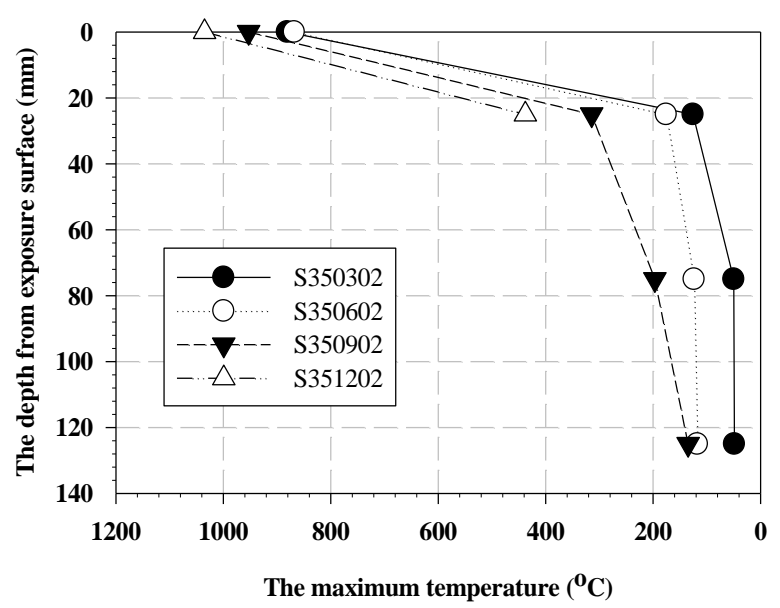

Fig. 12. The maximum temperature recorded at different depth levels for the $35 \mathrm{MPa}$ slab.

\subsection{Non-Destructive Test}

\subsubsection{Visual inspection}

The assessment began with visual observation of color change, cracking and spalling of the concrete surface. It was observed that cracks appeared on exposure surface in all slabs and the spalling area was larger on specimens that had longer fire exposure times (Table 3). Based on the data from the thermocouples on the exposed surfaces, all of the specimens were heated to over $800^{\circ} \mathrm{C}$. At this temperature, the cracks became very pronounced and increased extensively at $1000^{\circ} \mathrm{C}$ [9]. After exposure to the fire, the exposure surfaces showed a brighter color due to the limestone. At temperatures above $700^{\circ} \mathrm{C}$, carbonate aggregate decomposes into $\mathrm{CaO}$ and $\mathrm{CO}_{2}$ resulting in brighter colors due to the lime's whitish tint [21].

The second visual inspection determines the degree of damage on the exposure surfaces using a transparent plastic plate as mentioned above. The area of spalling was reported (Table 4) and compared with the control specimens in order to estimate the change caused by high temperatures. Next, an evaluation on the effect of fire exposure time to the degree of damage were drawn in Fig. 13. The graph shows that the increase in fire exposure time led to a raise in the degree of damage on the concrete surface. The area of spalling was not much different in the slabs exposed to fire for 30 and 60 minutes. Obtained values were less than $6 \%$, while the results from the other specimens were more than six times higher. A remarkable increase was recorded for the slabs exposed to fire for more than 90 minutes. This could be explained by the high 
temperatures impacting the slabs in cases of long fire exposure time as recorded in the profile of temperature distribution mentioned above.

The longer exposure time, the more spalling was observed on concrete surface, especially for samples with more than 90 minutes of exposure time. Meanwhile, the slabs with a heating time of 30 minutes exhibited the lowest values of damage. Another observation showed that the $35 \mathrm{MPa}$ slabs exhibited a higher degree of damage than the $24 \mathrm{MPa}$ slabs in all cases of exposure time. It is possible that the higher concrete grade specimens could be denser and therefore this might stop the water vapor inside the concrete from escaping from the concrete mass, which increases the susceptibility of spalling under fire conditions [22].

Table 3. The observation on fire exposed surface of specimens.

\begin{tabular}{lllll}
\hline S240002 & S240302 & S240602 & S240902 & S241202 \\
\hline & & & & \\
& & & & \\
\hline S350002 & S350302 & S350602 & S350902 & S351202 \\
\hline & & & & \\
& & & & \\
\end{tabular}

Table 4. The degree of damage on the surface exposed to fire.

\begin{tabular}{llll}
\hline Specimen No. & The damage degree (\%) & Specimen No. & The damage degree (\%) \\
\hline S240002 & - & S350002 & - \\
S240302 & 0 & S350302 & 3.3 \\
S240602 & 4.5 & S350602 & 5.7 \\
S240902 & 12.3 & S350902 & 43.1 \\
S241202 & 72.6 & S351202 & 83.6 \\
\hline
\end{tabular}

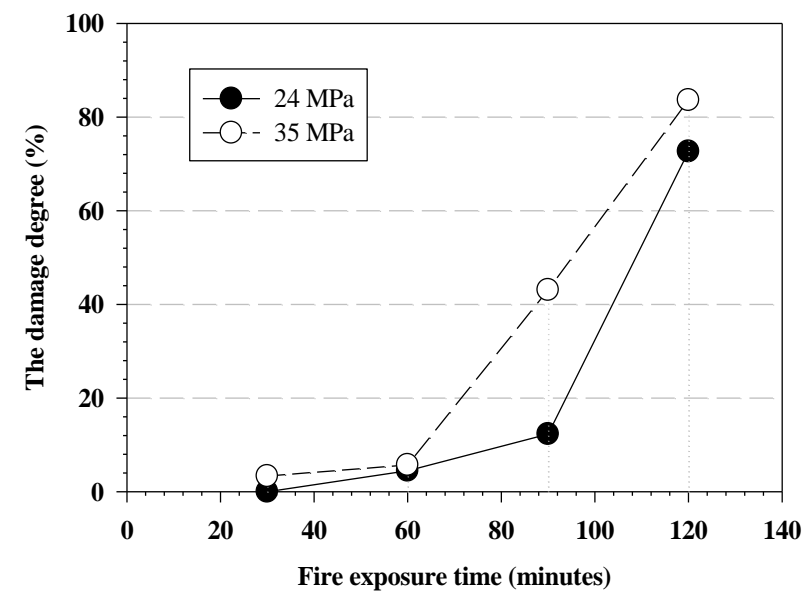

Fig. 13. The effect of fire exposure time to the damage degree.

\subsubsection{Ultrasonic pulse velocity (UPV) test}

The results from the UPV test showed that the intersection of the straight lines, corresponding with two paths as mentioned above, can be observed for specimens S240902 and S350902 as shown in Fig. 14. Therefore, the depths of fire-damaged layers calculated using Eq. (2) were $34.1 \mathrm{~mm}$ (S230902) and $56.1 \mathrm{~mm}$ 
(S350902). In contrast, only a straight line was observed in the graphs of control specimens (S240002 and S350002) since there were not damaged concrete layers in these cases (Fig. 14). In the other slabs, the intersection between the straight lines matching with two wave paths was not clearly observed. Consequently, values of the damaged concrete depth were not calculated for the slabs exposed to fire for 30,60 and 120 minutes.

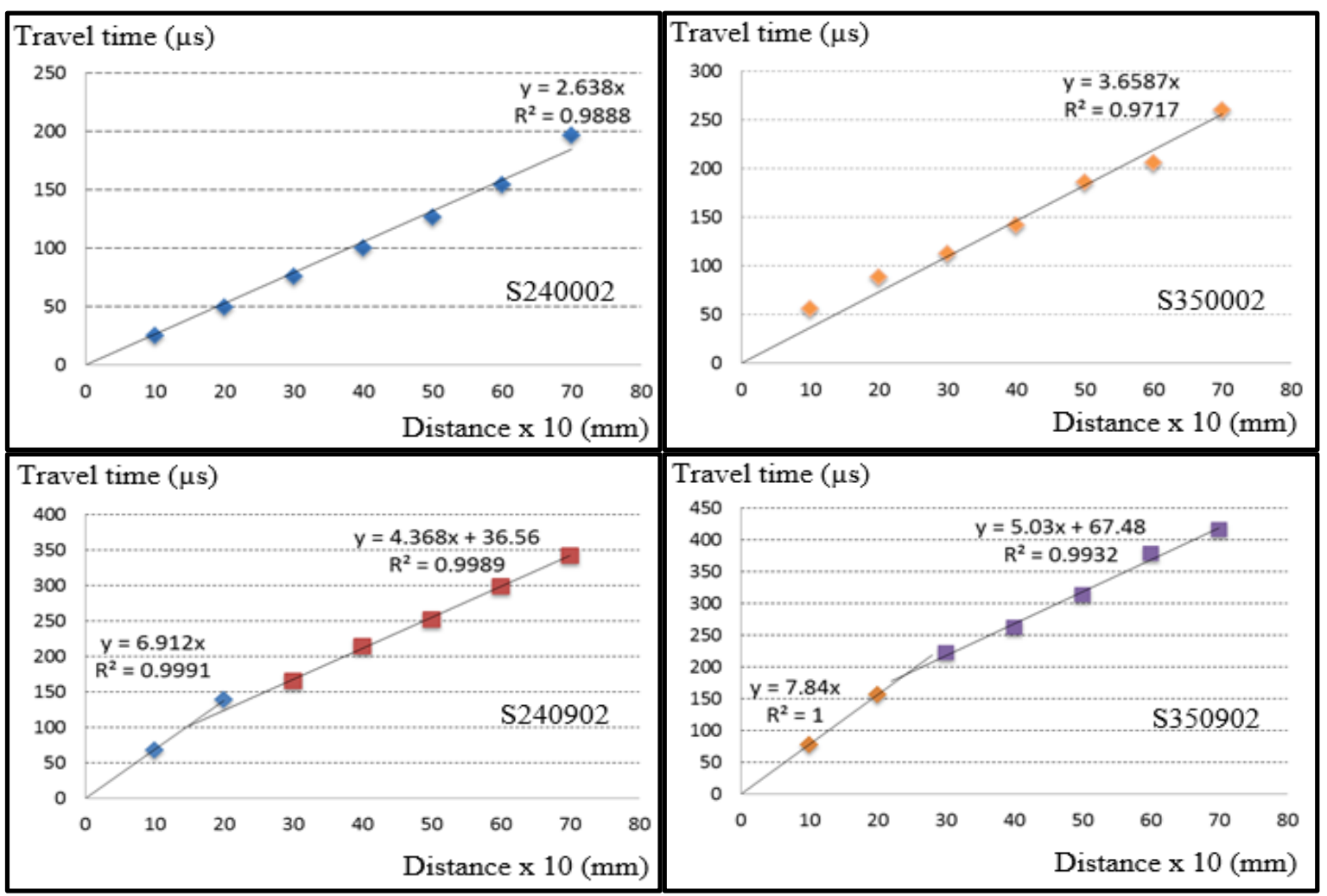

Fig. 14. Results of the UPV test.

\subsubsection{Schmidt rebound hammer test}

After testing by UPV, another situ technique (the Schmidt Rebound Hammer test) was used to determine the surface hardness of the concrete after fire exposure based on the rebound number recorded. The results of this test are reported in Table 5 and Fig. 15 in terms of the correlation between the rebound number and fire exposure time. In case of control specimens for the 24 and $35 \mathrm{MPa}$ slabs, the values of the rebound number were 35.9 and 40.1. Based on the chart in Fig. 15, the rebound number in two series of slabs decreased when the heating time was longer than 30 minutes. The lowest values obtained for the rebound number were below 30 in the slabs with a fire exposure time of 120 minutes.

As a result, longer fire exposure times resulted in lower rebound numbers, indicating more decrease in the concrete strength. These results were compatible with visual observation as the specimens with a long heating time showed higher degrees of damage on the concrete surface. Moreover, Fig. 16 shows the remaining rebound number (in percentage) of heated slabs compared to the results of control specimens. The results from the $35 \mathrm{MPa}$ slabs were lower than the values obtained from the $24 \mathrm{MPa}$ slabs. This indicates that the hardness of the surface on the $35 \mathrm{MPa}$ slabs is lower than the $24 \mathrm{MPa}$ slabs after fire exposure, which is similar to the results of the degree of damaged observed on the surface of the slabs as mentioned above. 
Table 5. The results of the Schmidt rebound hammer test.

\begin{tabular}{|c|c|c|c|c|c|}
\hline Specimen & $\begin{array}{l}\text { Rebound } \\
\text { Number }\end{array}$ & $\begin{array}{l}\text { Percentage } \\
\text { Change }(\%) \\
\end{array}$ & Specimen No. & $\begin{array}{l}\text { Rebound } \\
\text { Number }\end{array}$ & $\begin{array}{l}\text { Percentage } \\
\text { Change }(\%)\end{array}$ \\
\hline$\overline{\text { S240002 }}$ & 35.9 & 100.0 & S350002 & 40.1 & 100.0 \\
\hline S240302 & 36.2 & 100.8 & S350302 & 37.4 & 93.3 \\
\hline S240602 & 33.1 & 92.2 & S350602 & 34.0 & 84.8 \\
\hline S240902 & 30.4 & 84.7 & S350902 & 30.9 & 77.1 \\
\hline S241202 & 28.6 & 79.7 & S351202 & 29.7 & 74.1 \\
\hline
\end{tabular}

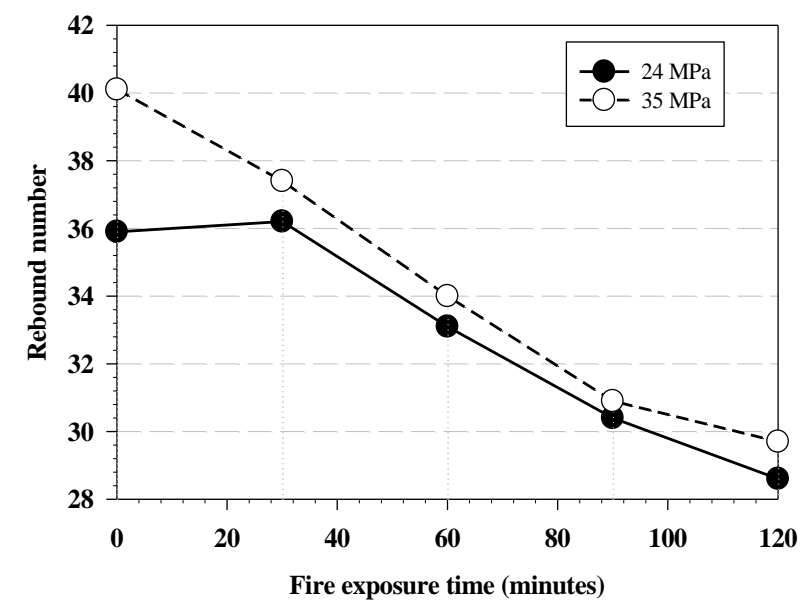

Fig. 15. The correlation between rebound number and fire exposure time.

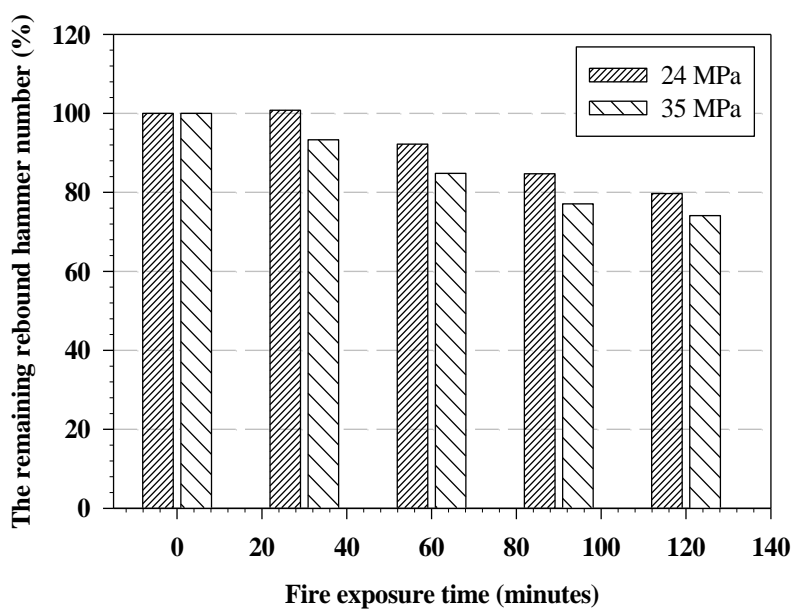

Fig. 16. The remaining rebound hammer number (\%).

\subsection{Destructive Test}

\subsubsection{Coring test}

To determine the depth of fire damage in the concrete layer, in addition to UPV testing, a coring test was performed to complement the data of color change in concrete due to fire. In normal conditions without exposing to fire, the color of the concrete is light gray. However, after heating above $300^{\circ} \mathrm{C}$, the color can change from normal to pink $\left(300-600^{\circ} \mathrm{C}\right)$ then to whitish gray $\left(600-900^{\circ} \mathrm{C}\right)$ and finally to buff $\left(900-1000^{\circ} \mathrm{C}\right)$ [6]. In this work, the color change on the coring specimens was estimated based on simple visual observation 
by eye and without using any special equipment. The observation aimed to distinguish the areas where the color of the concrete changed. This could demonstrate the parts that sustained high temperatures, which would lead to the change of components inside the concrete. Thus, concrete strength on those parts would be degraded.

In this test, concrete cores (diameter of $50 \mathrm{~mm}$ ) were drilled in each slab in order to measure the depth of color change inside the specimens (Fig. 17). The values are reported in Table 6. Based on the observation of color change in the concrete cores, the depth of color change increased as the fire time increased. With respect to the slabs fired in 30 minutes, the values were very small. Thus, it could be determined that a fire exposure time of 30 minutes did not result in much change inside the concrete.

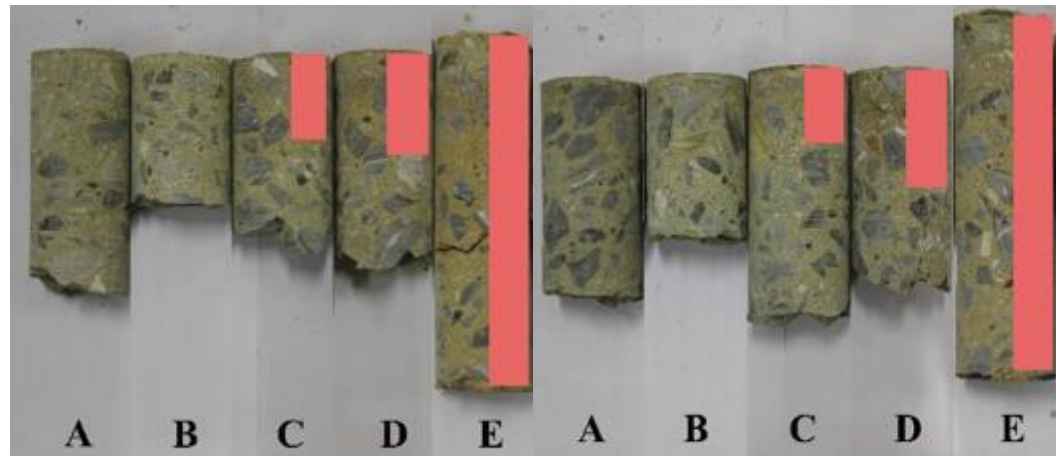

(a)

(b)

Fig. 17. Observation of the depths of color change in slabs $24 \mathrm{MPa}$ (a) and $35 \mathrm{MPa}$ (b).

Table 6. The depths of color change recorded.

\begin{tabular}{llll}
\hline Specimen No. & Depths of Color Change (mm) & Specimen No. & Depths of Color Change (mm) \\
\hline S240002 (A) & 0 & S350002 (A) & 0 \\
S240302 (B) & $<5$ & S350302 (B) & $<5$ \\
S240602 (C) & 35 & S350602 (C) & 29 \\
S240902 (D) & 45 & S350902 (D) & 42 \\
S241202 (E) & 150 & S351202 (E) & 150 \\
\hline
\end{tabular}

Moreover, referring to the temperature profile in Fig. 11 and Fig. 12, the specimens that were heated for 90 and 120 minutes shoed a temperature of over $300^{\circ} \mathrm{C}$ at a depth of $0-60 \mathrm{~mm}$ from exposure surface. When heating concrete above $300^{\circ} \mathrm{C}$, the color of concrete can change [6]. Therefore, the observation of the depth of color change in coring test was appropriate with the temperature obtained.

Meanwhile, the color change was observed in whole positions on concrete cores from the slabs heated in 120 minutes. Consequently, longer fire time such as more than 90 minutes could make change of components in all concrete parts of the slab even for the location far from exposure surface.

\subsubsection{Pull-off test}

The results from pull-off test in each slab are reported in Table 7. Except for the control specimens which were only tested at the surface, the test was carried out at four depth levels $(0,10,20,30 \mathrm{~mm}$ from the surface). Fig. 18 and Fig. 19 represent the values of pull-off strength obtained in the $24 \mathrm{MPa}$ and $35 \mathrm{MPa}$ slabs. 
Table 7. The results of pull-off test.

\begin{tabular}{lllll}
\hline \multirow{2}{*}{ Specimen No. } & Pull-off Strength (MPa) & & \\
\cline { 2 - 5 } & At surface of slab & At $\mathbf{1 0} \mathbf{~ m m}$ & At $\mathbf{2 0} \mathbf{~ m m}$ & At 30 $\mathbf{~ m m}$ \\
\hline S240002 & 2.55 & N/A & N/A & N/A \\
S240302 & 2.00 & 2.32 & 3.50 & 3.57 \\
S240602 & 0.86 & 0.94 & 0.94 & 1.17 \\
S240902 & 0.81 & 0.70 & 0.71 & 0.75 \\
S241202 & 0.36 & 0.56 & 0.66 & 0.65 \\
S350002 & 3.55 & N/A & N/A & N/A \\
S350302 & 1.32 & 1.48 & 2.41 & 2.45 \\
S350602 & 0.44 & 0.93 & 1.33 & 1.82 \\
S350902 & 0.41 & 0.92 & 1.19 & 1.26 \\
S351202 & 0.37 & 0.41 & 0.64 & 0.85 \\
\hline
\end{tabular}

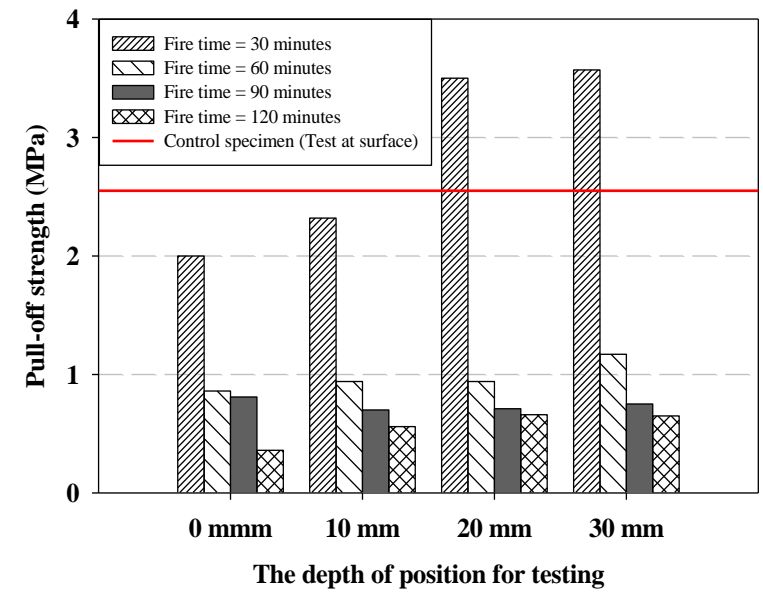

Fig. 18. The effect of fire exposure time to the pull-off strength in specimens of $24 \mathrm{MPa}$.

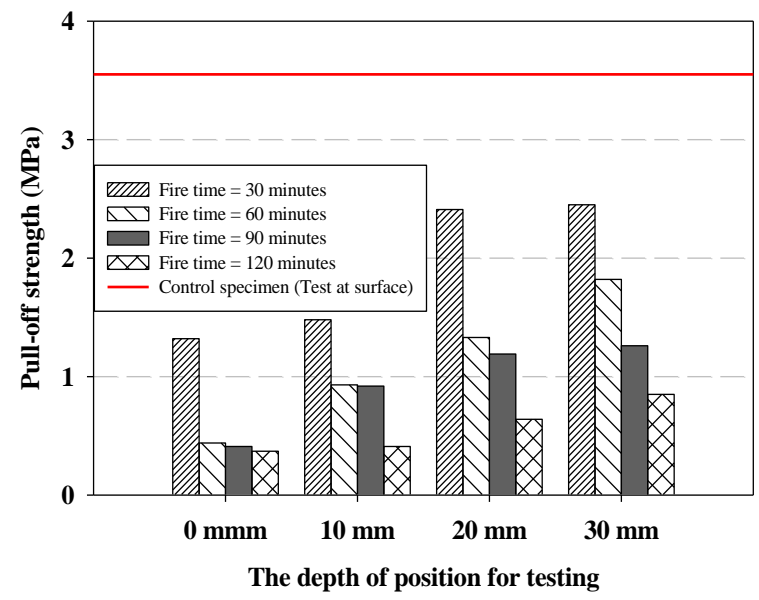

Fig. 19. The effect of fire exposure time to the pull-off strength in specimens of $35 \mathrm{MPa}$.

From those figures, it can be seen that the pull-off strengths achieved in specimens with fire exposure time of 30 minutes were significantly higher than the other specimens. This occurred at all of depth levels in both concrete grades. Therefore, the long exposure time (of more than 30 minutes) causes a serious decrease in tensile strength of concrete with the lowest strength value obtained after the longest heating time (120 
minutes). In general, at each depth level, the pull-off strengths decreased corresponding with the increase in fire exposure time.

In addition, an increase in the pull-off strength at further depth levels was observed for each case of fire time. This is due to the decreased detrimental effect of fire at positions farther from the exposure surface as the temperature decreased at deeper concrete layers, as recorded by the thermocouple. Considering the 24 MPa specimens with a heating time of 30 minutes, the pull-off strength at the surface and a depth of $10 \mathrm{~mm}$ were lower than the results obtained from the control specimen. However, higher values were recorded at the depths of 20 and $30 \mathrm{~mm}$. On the other hand, the pull-off strengths at all evaluated depths of $35 \mathrm{MPa}$ slabs were lower than the value of control specimens.

\subsection{Evaluation of the Fire-Damaged Depth}

For the purpose of repairing slabs exposed to fire, the damaged concrete layer should be determined and replaced by new material. Following the guide of fib Bulletin 46, the tensile strength of the new concrete layers should be assessed, and pull-off testing can be used, where the minimum value for the pull-off strength of the concrete substrate is $1.5 \mathrm{MPa}$ [20]. Thus, in combination with the depth of color change and the damaged depth predicted from UPV testing, the minimum depth of deteriorated layer that should be removed (h) for each slab could be estimated.

However, UPV testing did not provide reliable data due to the lack of values for the damaged depth calculated from the test. Based on the experiment in this study, it is strongly recommended to conduct pulloff testing and core testing in order to evaluate the damaged concrete depth due to fire. The values of $h$ are reported in Table 8 for each fire exposure time.

Table 8. The damaged depth that should be removed.

\begin{tabular}{|c|c|c|c|c|c|c|}
\hline \multirow[b]{2}{*}{$\begin{array}{l}\text { Fire time } \\
\text { (Minutes) }\end{array}$} & \multicolumn{3}{|l|}{ Slab $24 \mathrm{MPa}$} & \multicolumn{3}{|l|}{ Slab $35 \mathrm{MPa}$} \\
\hline & $\begin{array}{l}\text { The depth of } \\
\text { color change } \\
(\mathrm{mm})\end{array}$ & $\begin{array}{l}\text { The depth }(\mathrm{mm}) \\
\text { where pull-off } \\
\text { strength reaches } 1.5 \\
\mathrm{MPa}\end{array}$ & $\begin{array}{l}\text { h } \\
(\mathrm{mm})\end{array}$ & $\begin{array}{l}\text { The depth of } \\
\text { color change } \\
(\mathrm{mm})\end{array}$ & $\begin{array}{l}\text { The depth }(\mathrm{mm}) \\
\text { where pull-off } \\
\text { strength reaches } 1.5 \\
\mathrm{MPa}\end{array}$ & $\begin{array}{l}\text { h } \\
(\mathrm{mm})\end{array}$ \\
\hline 30 & $<5$ & $\mathrm{NO}$ & 5 & $<5$ & $20 \mathrm{~mm}$ & 20 \\
\hline 60 & 35 & Deeper than $30 \mathrm{~mm}$ & 35 & 29 & $30 \mathrm{~mm}$ & 30 \\
\hline 90 & 45 & Deeper than $30 \mathrm{~mm}$ & 45 & 42 & Deeper than $30 \mathrm{~mm}$ & 42 \\
\hline 120 & 150 & Deeper than $30 \mathrm{~mm}$ & 150 & 150 & Deeper than $30 \mathrm{~mm}$ & 150 \\
\hline
\end{tabular}

\section{Conclusions}

The following conclusions can be drawn from the present study:

The longer the fire exposure time, the higher degree of damage on the exposure surface. However, 30 minutes of heating time did not show severe effects on reinforced concrete slabs in comparison with the cases of 60,90 and 120 minutes of fire exposure time.

Regarding to the compressive strength of concrete after fire, testing was conducted on the surface of slabs using the Schmidt Rebound Hammer method. $24 \mathrm{MPa}$ specimens obtained higher values than $35 \mathrm{MPa}$ slabs. Moreover, $24 \mathrm{MPa}$ slabs also showed a lower degree of damage on the exposure surface.

To determine the depth of the damaged concrete layer that should be removed, a comparison of the results from UPV, pull-off tests and coring tests was carried out. The study recommends not using only UPV testing to calculate the damaged concrete depth. Pull-off testing in combination with the observation of coring specimens should be carried out to provide reliable values for purposes such as strengthening or repairing structure.

Based on these results, the influence of fire on $24 \mathrm{MPa}$ slabs with 30 minutes of heating time was not serious and the damaged depth was insignificant. Therefore, repairing the slab in this case might only require the renewing of the surface exposed to fire. However, a damaged layer of $20 \mathrm{~mm}$ should be removed for 35 MPa slabs having same fire exposure time.

A damaged concrete layer of $30-35 \mathrm{~mm}$ was observed for slabs exposed to fire for 60 minutes. At 90 minutes exposure time, values of 45 and $42 \mathrm{~mm}$ of damage depths were obtained for with 24 and $35 \mathrm{MPa}$ 
slabs. Especially as heating time increased over 120 minutes, it could make more serious effect to whole concrete area of the slab.

The experimental data in this study could be used as a reference for works aiming to repair RC slab structures after fire exposure. If the slab expose to fire longer than 30 minutes, it is necessary to replace a damaged concrete layer that can be determined by NDT and DT techniques as mentioned above. On the other hand, lower concrete grade slab showed lower damage level based on the experimental in this research.

In further research, the effect of concrete covers should be considered to propose an effective value for $\mathrm{RC}$ slab to diminish loss and increase the potential for reusing the structure.

\section{Acknowledgment}

The authors acknowledge the support provided by Retrofit Structure Specialist Co., Ltd. The authors would also like to acknowledge the support received from Chulalongkorn University with a scholarship of the CUASEAN program and "Stimulus Package 2 (SP2) of Ministry of Education under the theme of "Green Engineering for Green Society" of Thailand.

\section{References}

[1] N. Short, J. Purkiss, and S. Guise, "Assessment of fire damaged concrete using colour image analysis," Construction and Building Materials, vol. 15, pp. 9-15, 2001.

[2] E. V. Annerel and L. R. Taerwe, "Assessment techniques for the evaluation of concrete structures after fire," Journal of Structural Fire Engineering, vol. 4, pp. 123-30, 2013.

[3] J. P. Ingham, "Application of Petrographic Examination Techniques to the Assessment of FireDamaged Concrete and Masonry Structures," Materials Characterization, vol. 60, pp. 700-9, 2009.

[4] Fédération internationale du béton (fib), Fire Design of Concrete Structures-Materials, Structures and Modelling. Switzerland: The International Federation for Structural Concrete (fib), 2007.

[5] J. Newman and B. S. Choo, Advanced Concrete Technology, Volume 2: Concrete Properties. Elsevier Science \& Technology, 2003.

[6] B. Georgali and P. Tsakiridis, "Microstructure of fire-damaged concrete. A case study. Cement and Concrete Composites. 2005;27:255-9.

[7] B. Erlin, W. G. Hime, and W. H. Kuenning, "Evaluating fire damage to concrete structures," Concrete Construction, vol. 17, pp. 154-9, 1972.

[8] A. Gustaferro, "Experiences from evaluating fire-damaged concrete structures," ACI Special Publication, vol. 80, pp. 269-278, 1983.

[9] O. Arioz, "Effects of elevated temperatures on properties of concrete," Fire Safety Journal, vol. 42, pp. 516-22, 2007.

[10] J. Dougill, "The effect of high temperature on concrete with reference to thermal spalling," Ph.D. thesis, Imperial College, London, 1971.

[11] M. Gary, Fire Tests on Reinforced Concrete Buildings. Verlag Wilhelm Ernst und Sohn, 1916.

[12] R. J. Connolly, "The spalling of concrete in fires," Doctoral disseration, Aston University, 1995.

[13] S. E. Guise, "Use of colour image analysis for assessment of fire damaged concrete," Dcotorla disseration, Aston University, 1997.

[14] ACI, ACI 318-08: Building Code Requirements for Structural Concrete and Commentary. USA: American Concrete Institute, 2008, p. 345.

[15] ASTM, ASTM C805 / C805M-13a: Standard Test Methods for Rebound Number of Hardened Concrete. West Conshohocken, USA: American Society for Testing and Materials, 2013.

[16] ACI, ACI 228.2R-98: Nondestructive Test Methods for Evaluation of Concrete in Structures. USA: American Concrete Institute, 1998.

[17] M. Tuncan, O. Arioz, K. Ramyar, and B. Karasu, "Assessing concrete strength by means of small diameter cores," Construction and Building Materials, vol. 22, pp. 981-8, 2008.

[18] ASTM, ASTM C 42/C 42M - 03: Standard Test Method for Obtaining and Testing Drilled Cores and Sawed Beams of Concrete, West Conshohocken, USA: American Society for Testing and Materials, 2003.

[19] ASTM, ASTM C 1583 - 04: Standard Test Method for Tensile Strength of Concrete Surfaces and the Bond Strength or Tensile Strength of Concrete Repair and Overlay Materials by Direct Tension (Pull-off Method). West Conshohocken, USA: American Society for Testing and Materials, 2004. 
[20] Fédération internationale du béton (fib), Fire Design of Concrete Structures-Structural Behaviour and Assessment. Switzerland: The International Federation for Structural Concrete (fib), 2008.

[21] I. Hager, "Colour change in heated concrete," Fire Technology, vol. 50, pp. 945-58, 2014.

[22] F. Ali, "Is high strength concrete more susceptible to explosive spalling than normal strength concrete in fire?," Fire and Materials, vol. 26, pp. 127-30, 2002. 